\title{
Flexible pavement design of district road
}

\author{
S. VenkatCharyulu and G.K.Viswanadh ${ }^{2}$ \\ ${ }^{1}$ Assistant professor Gokaraju RangaRaju Institute of Engineering \& Technology Hyderabad, India and Research scholar, \\ Department of Civil Engineering, JNTUH, Kukatpally, Hyderabad, India , \\ ${ }^{2}$ Professor of Civil Engineering and Director, UGC-HRDC JNTUH, Kukatpally, Hyderabad, India,
}

\begin{abstract}
In nowadays it is very important to have a proper road network for the purpose of good transportation. Few places road network is not available while the traffic is higher and enough. Pavement is generally being constructed and used for the purpose of smooth and comfort moment of the traffic. Flexible pavements will be subjected to load by wheel develop stress particles-to-particles transmit to the lower grades of layers through the granular structure. The pavement is subjected to the wheel loading action on it and the load is to be distributed to a larger area, such that the decrease in stress will occur with respect to the depth. The patch considered in this project is of KKY District Road. [KKY-Karimnagar Kamareddy Yellareddy]. The current condition of the KKY road is very much disturbed with the presence of uneven undulations as heavy loaded vehicles like moment of trucks took part. Hence, for the purpose of the fulfilment of all the above requirement factors and for the comfort moment of traffic. Adopted the effective design of flexible pavement. In this paper, we are enclosing the design report KKY road which includes all the which comes under the project of the pavement construction.
\end{abstract}

\section{Introduction}

Flexible pavement by CBR Method is consists of processed materials of super imposed layers, which are above the soil sub-grade. The main objective of this road is to transfer the vehicular load to the lower layers. The purpose of pavement to provide adequate skid resistance, require surface riding quality, lessnoise pollution and more reflecting character. The ultimate function of the pavement structure to reduce the transmitted stresses due to wheel, different layers, their structure functions loads, by this process bearing capacity of the subgrade will not be exceed. There are two general types of pavement, one is Flexible Pavement other one is Rigid Pavement. In this project we found an overview of types of pavementsand failure of pavements. Improper pavement design leads to pavement failure, which affects the riding quality.

\section{Literature review}

Designing flexible pavements including cross drainage works of a village road near suburb of Bhuneshwar Tharun Kumar lohani subesis pati and Prasanta Kumar parida(2019) Connecting road designed and estimated at the least price providing the localized material for the sub-grade which is morrum in nature from the traffic value survey the commercial vehicle per day has been obtained. Most part to conclude that a safe and durable road with culverts have been designed taking all the technical specifications into consideration. Flexible pavement for NH-7 of Nagpur-Hyderabad(123km to $175 \mathrm{~km})$ $\mathrm{CH}$.Balakrishna, $\mathrm{M}$.Anvesh kumar. The designed is carried out by the overall traffic summed up to the end of the day. "Flexible pavement design using Industrial waste Vishal Mathematic, Vishwanath Awati," Assistant professor ,Dept of Civil Engineering, JCE, Belagavi In this project we used fly ash as a soil stabilizing material with alternative material as cement. Design of Journal of Core Engineering and Management (IJCEM)-2 May 2016 By Ritu Shingloo. Subagio (2005) discuss multilayer pavement 1 analysis of structure using equivalent thickness method. A method has developed to estimate the stresses and strains in multiple layers pavement system. Construction of flexible pavements by RIYANTO (1996) was pavement using asphalts as a surface. Defects inflexible pavement and its maintenance by "Zulfiqar Bin Rashid" and "Rakesh Gupta". J.M Sadeghi et.al (2007) "Deterioration analysis of flexible pavement construction a is importent for the safety of vehicle movement. N. Jain "vehicle axle loading pattern on state roads of Uttar Pradesh". (2009). R. B. Mallick, et.al, "use of empirical roads design software (2006). 
$>$ To provide the road which can withstand the expected traffic loading

$>$ To limit the stresses induced in the subgrade by traffic to a safe level

$>$ To provide the surface that can be strong on surface strength and in moisture content

$>$ To provide the surface that is smooth

$>$ The surface should be safe in friction and drainage

$>$ Flexible pavements can take maximum load carrying capacity in the form of load magnitude

$>$ Flexible pavement is designed to protect the subgrade of road and to avoid tensile stresses.

\section{Methodology}

Alignment of the road is done by road surveying and details are mentioned in the report. Technical features of the project such as details of right of the way, No. of lanes, carriageway width, shoulder width are clearly mentioned according to the design of the pavement. All the required dimensions of the cross sectional elements of the road are calculated and mentioned accordingly. Traffic survey report on KKY road is made through manual counting of the traffic moments of the road. And a design period of 20 years is assumed based on the design data. Tests are to be conducted on bitumen, aggregates and sub soil for the pavement in the near by treatment plant and results been calculated. Finally design data of the road the KKY road is calculated and design procedure is mentioned. A complete report on KKY road is enclosed in this project.

\section{Necessity of a pavement}

An ideal pavement should satisfy the following requirements:

$>$ Thickness should be sufficient for distributing the stresses of wheel load on the sub-grade soil to a safe value.

$>$ It should be strong structurally to withstand all types of stresses subjected upon it

$>$ Friction coefficient must be adequate to avoid skidding of vehicles

$>$ Surface to be smooth for the comfortable provision of road to the users often at high speed

$>$ Impervious surface, so that sub-grade soil is well protected

$>$ It should have a design life with long period at minimum maintenance cost.

5.1 Advantages of flexible pavement

$>$ It provides the possibility of low cost type construction
It will have a greater resistance to fluctuations of temperature. Repair works can be conducted easily for the flexible pavement.

$>$ The thickness of the road can be easily increased according to the convenience. Less wear to the tire and less fuel consumption and smoother ride .Materials are inexpensive. It duration time is short. Resists ice glaze formation.

\subsection{Technical features of the project}

- $\quad$ Project Right of way $=18.5 \mathrm{~m}$, No. of lanes $=2$

- $\quad$ Carriageway width $=7 \mathrm{~m}$, Divider width $=.5 \mathrm{~m}$

- $\quad$ Shoulder width $=1.5 \mathrm{~m}$

\subsection{Pavement details}

Main Carriageway:

- Bituminous Concrete $(\mathrm{BC})=45 \mathrm{~mm}$ (becomes $35 \mathrm{~mm}$ after compaction)

- Dense Bituminous Macadam $=75 \mathrm{~mm}$ (becomes $60 \mathrm{~mm}$ after compaction)

- Wet Mix Macadam $(\mathrm{WMM})=250 \mathrm{~mm}$

- Granular Sub-Base $(\mathrm{GSB})=250 \mathrm{~mm}$

- $\quad$ Sub-Grade $(\mathrm{SG})=1000 \mathrm{~mm}($ Gravel$-500 \mathrm{~mm})$

\subsection{Project road and approved department}

The Road of Karimnagar Kamareddy Yellareddy (KKY) which is reach from KM $72 / 8$ to $102 / 0$ have been awarded to the following

\subsection{Location plan of the project}

There are mainly two types of pavements, Flexible Pavement, Rigid Pavement . The Pavements which are flexible in their structural action and have minimum flexural strength under the loads, such pavements are called as Flexible Pavements.where as The Pavements which do not have flexural strength and the stresses are not transferred to the lower layers. Rigid Pavements are constructed by Portland cement concrete or plain concrete. About $40 \mathrm{~kg} / \mathrm{cm}^{2}$ flexural stresses is taken by plain cement concrete slab. Slab action can be seen in Rigid Pavements and it has capability of transmitting heavy stresses of wheel load with a wider area. The study area has following details shown in figure 1 and details as given as 


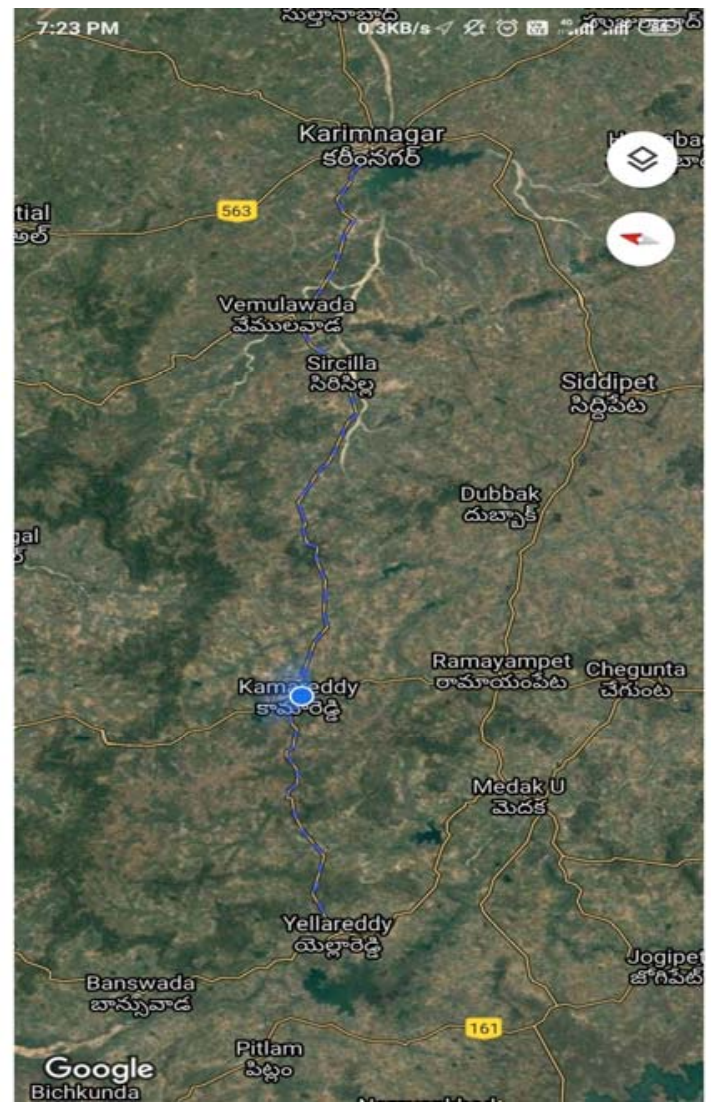

Fig.1 KKY ROAD (Google source)

From 97/4 NH (national highway) to 99/4 total length of $2 \mathrm{~km}$ under permission authority of Roads \& Buildings (R\&B) Sub-Division, Kamareddy, Telangana state, India.

\section{Functions of flexible pavement}

Components are Soil Sub grade, Sub-Base, Course, Base Course, and Wearing Course. Soil sub grade is a large naturally obtained soil, provided to receive the different layers of materials for the pavement to laid over it. Subgrade is the lower most layer which ultimately receives the whole load of the pavement. The pressure is transmitted on the top most layer of the subgrade and must satisfy the limit of allowance, such that there will be no excess stress condition or any deformations beyond the limit of elasticity. It is very vital to compute the strength properties of the sub - grade soil. This helps in designing the structure for a great strength with the suitable values. Sub base is a course provided under the base course. The principle of Sub-base course is to attain the structural support, drainage improvement, and to minimize the fine intrusion from the sub grade in the structure of pavement. The thickness of sub base course is $20 \mathrm{~cm}$. The base course is the layer of material which is provided under the binder course and it provides additional load to the sub-surface drainage. Base course is a mixer of crushed stone, crushed slag and other untreated materials. Wearing course purpose is to maintain smooth riding surface. It resists the pressure exerted by tyres and takes up wear and tear due to traffic. Wearing course act as a water tight layer against the surface infiltration.

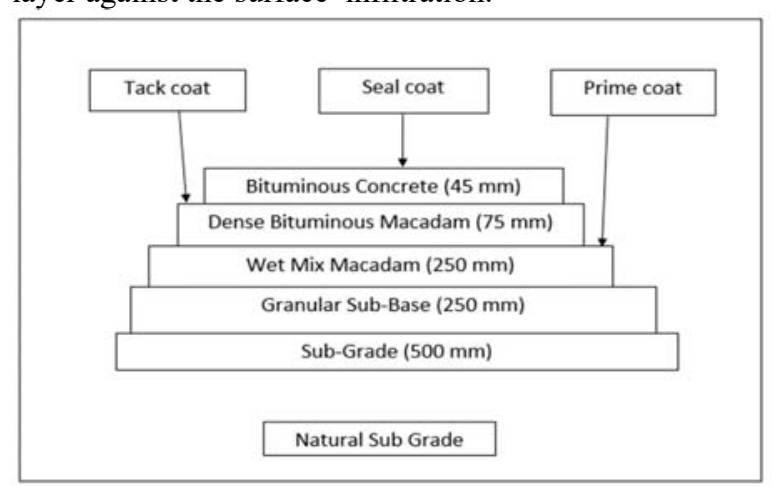

Fig..2 Lay out of the pavement cross section (Google source)

\subsection{Road alignment}

The position of Centre line of pavement is known as Alignment of the Road. The disadvantages due to improper alignment are, Maintenance cost of road .iincreased, Vehicle operation cost also increased, Accident cost is increased. The requirements of Alignment is Safe and Economical. Road alignment should be short and easy for convenient moment of traffic. It should attain a safety to the users and must be economical. Alignment should reduce number of turnings to reduce the road length. Once the road is aligned and constructed, it is not easy to change the alignment due to increase in the cost of structure. Therefore road must be levelled by conducting road survey. Figure 2 shows the details of pavement crosssection

Table1. Levels of the road with chinage distance.

\begin{tabular}{|c|c|c|c|c|c|c|c|}
\hline 9 & & & IS & & & & \\
\hline $\begin{array}{l}\text { Chai- } \\
\text { nage }\end{array}$ & $\mathbf{S}$ & Left & Cen & Righ & F.S & R.L & Rem \\
\hline 0 & $\begin{array}{l}0 . \\
92\end{array}$ & 1.700 & 1.701 & 1.716 & & 99.21 & $\begin{array}{l}100.9 \\
2\end{array}$ \\
\hline 10 & & 1.710 & 1.722 & 1.720 & & 99.19 & \\
\hline 20 & & 1.725 & 1.740 & 1.775 & & 99.18 & \\
\hline 30 & & 1.825 & 1.857 & 1.895 & & 99.06 & \\
\hline 40 & & 2.050 & 2.060 & 2.090 & & 98.86 & \\
\hline 50 & & 2.190 & 2.180 & 2.200 & & 98.74 & \\
\hline 60 & & 2.410 & 2.345 & 2.355 & & 98.58 & \\
\hline 70 & & 2.490 & 2.480 & 2.465 & & 98.44 & \\
\hline 80 & & 2.700 & 2.680 & 2.650 & & 98.24 & \\
\hline
\end{tabular}




\begin{tabular}{|l|l|l|l|l|l|l|l|}
\hline 90 & & 2.850 & 2.730 & 2.700 & & 98.19 & \\
\hline 100 & & 8.015 & 3.000 & 3.050 & & 97.92 & \\
\hline 110 & & 3.250 & 3.235 & 3.000 & 3.215 & 97.69 & 97.7 \\
\hline 120 & & 1.640 & 1.630 & 1.630 & & 97.53 & 99.1 \\
\hline 130 & & 1.950 & 1.865 & 1.895 & & 97.30 & \\
\hline 140 & & 2.150 & 2.050 & 2.020 & & 97.11 & \\
\hline 150 & & 2.505 & 2.300 & 2.270 & & 96.86 & \\
\hline 160 & & 2.655 & 2.570 & & 2.610 & 96.59 & \\
\hline 170 & & 2.940 & 2.860 & 2.770 & & 96.30 & \\
\hline 180 & & 3.080 & 3.020 & 3.035 & & 96.14 & \\
\hline 190 & & 3.170 & 3.155 & 3.150 & & 96.00 & \\
\hline
\end{tabular}

\begin{tabular}{|c|c|c|c|c|c|c|l|}
\hline S1.No. & \multicolumn{2}{|l|}{ Road Classification } & \multicolumn{2}{l}{ Right Lane (m) } & \multicolumn{2}{l}{} \\
\hline 1. & \multicolumn{2}{|c|}{ KKY Road } & \multicolumn{2}{|c|}{18.5} & \multicolumn{2}{l}{} \\
\hline 200 & & 3.410 & 3.255 & 3.310 & & 95.90 & \\
\hline 210 & & 3.390 & 3.395 & 3.340 & & 95.76 & \\
\hline 220 & & 3.610 & 3.560 & 3.600 & & 95.60 & \\
\hline 230 & & 3.700 & 3.650 & 3.685 & & 95.51 & \\
\hline 240 & & 1.450 & 1.370 & 1.376 & & 95.57 & \\
\hline 250 & & 1.365 & 1.355 & 1.365 & & 95.59 & \\
\hline 260 & & 1.290 & 1.325 & 1.315 & & 95.62 & \\
\hline 270 & & 1.365 & 1.255 & 1.255 & & 95.69 & \\
\hline 280 & & 1.350 & 1.400 & 1.275 & & 95.54 & \\
\hline 290 & & 1.395 & 1.440 & 1.410 & & 95.50 & \\
\hline 300 & & 1.350 & 1.460 & 1.390 & & 95.48 & \\
\hline 310 & & 1.520 & 1.450 & 1.365 & & 95.49 & \\
\hline 320 & & 1.740 & 1.670 & 1.615 & & 95.27 & \\
\hline 330 & & 1.610 & 1.510 & 1.310 & & 95.43 & \\
\hline & & & & & & & \\
\hline
\end{tabular}

\subsection{Calculations}

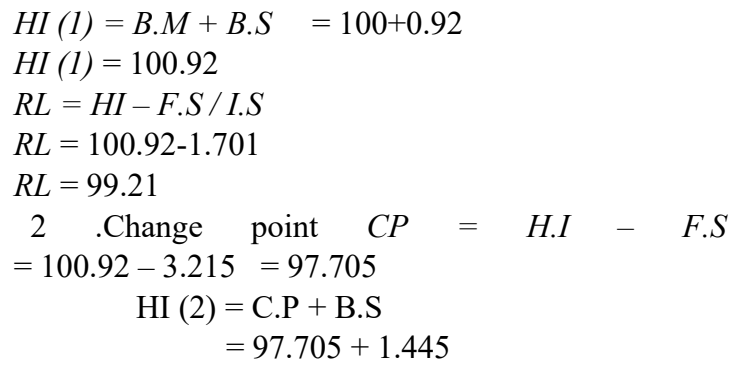

$=99.16$

CHECK:

B.S - F.S $=$ Last $R L-$ First $R L$

$(0.92+1.445)-(3.215+2.610)=95.43-99.21$

$2.365-5.825=3.78$

$3.78=3.78$

L.HS = R.H.S

The Table 1 shows the road length measurement chainage ( length),BS ( Back sight),IS(inter mediate sight), FS(fore sight), RL (reduced levels, Cen (center line). HI(hight of instrument

\section{Cross sectional elements}

\subsection{Road land width}

Road land width is also termed as "RIGHT-OFWAY". The width of land acquired for the road purposes is not is known as Right-of-Way. The desirable land width for the Road KKY is given in the following table

Table 2 Road and lane width .

\subsection{Lane width}

As per the standard specifications of IRC, 731980 , the recommended lane width is $3.5 \mathrm{~m}$ for single lane and $7 \mathrm{~m}$ for double lane. California state highway standards allows for $3.6 \mathrm{~m}$ wide lanes for single lane and $7.5 \mathrm{~m}$ wide for double lane. Since the KKY Road is going to be a high speed facility for the free flow of traffic moment, it was felt necessary to provide the lane width according to the standards as follows.

Table 3. Lane width

\begin{tabular}{|l|l|}
\hline Lane & Lane width (m) \\
\hline Left lane & 7 \\
\hline Right lane & 7 \\
\hline
\end{tabular}

\subsection{Width of the shoulder}

Shoulders are provided on either side of the carriageway and it plays a very important role in the capacity of the carriageway. The shoulders, so provided not only as emergency lane but also act as parking lanes. Since, the vehicles will be parked on the shoulders, they will not abstruct the free mome of the traffic on the carriageway. The width of the Road $\mathrm{KKY}$ is given in the Table 3 as follows, 
Table 5 Traffic details

Table 4. Shoulder width

\begin{tabular}{|l|l|}
\hline Type of shoulder & Shoulder width \\
\hline Earthen shoulder & $1.5 \mathrm{~m}$ \\
\hline
\end{tabular}

When the traffic increases about 2000 vehicles/day, it is necessary to increase the width of the paved shoulder in excess of $3 \mathrm{~m}$. In the present case of KKY road, earthen shoulders of $1.5 \mathrm{~m}$ are provided, which can be easily modified to paved shoulders whenever required in the future. Table 4 shown in the width .

\subsection{Camber}

The slope provided to the surface of the road which has to be at the transverse direction is said to be camber. The primary function of the camber is to drain out the rainwater from the road surface around the edges. It is also termed as cross slope of the road. The design values of the cross slope are usually based on the type of pavement and often on the average rainfall amount in the particular area. In present case of KKY road, $5 \mathrm{~mm}$ of camber is provided on the average value of the Bituminous Concrete (BC) on the carriageway.

\section{Traffic survey}

An accurate estimate of the traffic is very essential for the design of a road pavement and for the complete project report on the road. It includes planning, designing, operation and financing. Traffic survey is carried out to assess the present day traffic and its characteristics. Traffic volume is No. of vehicles crossing a section of road in unit times is known as Traffic volume. Unit is Vehicle/hour per lane Or Vehicle/day per lane.

\subsection{Method of volume counting}

I. Manual method

II. Automatic Record method

$>$ Manual method The vehicles crossing over a particular section of the road are to be counted manually and noted down clearly. A manual calculation is made to count the vehicles which passes over, in a particular unit time.

Automatic record method In this method, the no. of vehicles crossing over a section are counted automatically through videographs. These videographs will shoot the vehicles moment and MS ROADS is the software used to calculate the traffic flow based on the videographs taken. The Table 5 shows the traffic details of study area.

\begin{tabular}{|l|l|l|l|l|}
\hline LOCATION & $\begin{array}{l}\text { Two } \\
\text { Wheel } \\
\text { Vehicles }\end{array}$ & $\begin{array}{l}\text { Three } \\
\text { Wheel } \\
\text { Vehicles }\end{array}$ & $\begin{array}{l}\text { Four } \\
\text { Wheel } \\
\text { Vehicles }\end{array}$ & $\begin{array}{l}\text { Heavy } \\
\text { Loaded } \\
\text { Vehicles }\end{array}$ \\
\hline $\begin{array}{l}\text { Nizamsagar } \\
\text { Road }\end{array}$ & 3356 & 2786 & 2160 & 9 \\
\hline $\begin{array}{l}\text { Layola } \\
\text { School }\end{array}$ & 2948 & 2377 & 1901 & 7 \\
\hline Jeevadhan & 3464 & 2896 & 1822 & 7 \\
\hline Kalkinagar & 2685 & 2432 & 1720 & 6 \\
\hline Devunpally & 1829 & 2004 & 296 & 10 \\
\hline Lingapur & 709 & 1964 & 222 & 8 \\
\hline
\end{tabular}

\subsection{Design period}

A 20 years design period (2021-2041) is assumed for the design on flexible pavement of KKY road.

\subsection{Required tests}

We have different types of tests to identify the properties of soil and bitumen in pavement construction. Following are the tests required for soil and bitumen. Sieve Analysis, Bitumen, Extraction test, CBR test, Penetration test. Sieve analysis is done to find out the distribution of the coarser layers of different size particles. Sieve analysis can be carried out by Take the sample and weight the sample. All sieves must be cleaned.. Sieves are arranged in ascending order. And also pan is placed below sieves .In top sieve sample is placed and cover it with cap. Place this sieves in sieve shaker and shake it for 10 minutes. Remove the sieves from shaker and note down the each weight of sieve and also weigh sample. Table 5 shows the results of the sieve analysis.

Table 5. Observations and calculations

\begin{tabular}{|l|l|l|l|l|}
\hline $\begin{array}{l}\text { Sieve } \\
\text { size }\end{array}$ & $\begin{array}{l}\text { Weigh } \\
\text { t } \\
\text { retaine } \\
\text { d }\end{array}$ & $\begin{array}{l}\text { \%weig } \\
\text { ht } \\
\text { retaine } \\
\text { d }\end{array}$ & $\begin{array}{l}\text { Cummulati } \\
\text { ve } \\
\text { weight } \\
\text { retained }\end{array}$ & $\begin{array}{l}\text { \% } \\
\text { finene } \\
\text { ss }\end{array}$ \\
\hline $40 \mathrm{~mm}$ & $10 \mathrm{~kg}$ & $10 \%$ & $10 \%$ & $90 \%$ \\
\hline $20 \mathrm{~mm}$ & $35 \mathrm{~kg}$ & $35 \%$ & $45 \%$ & $55 \%$ \\
\hline $12 \mathrm{~mm}$ & $25 \mathrm{~kg}$ & $25 \%$ & $70 \%$ & $30 \%$ \\
\hline $10 \mathrm{~mm}$ & $20 \mathrm{~kg}$ & $20 \%$ & $90 \%$ & $10 \%$ \\
\hline $\begin{array}{l}4.75 \mathrm{~m} \\
\mathrm{~m}\end{array}$ & $10 \mathrm{~kg}$ & $10 \%$ & $100 \%$ & $0 \%$ \\
\hline Total & $100 \mathrm{~kg}$ & & $315 \%$ & \\
\hline
\end{tabular}




\subsection{1 cbr test}

To determine the bearing capacity of a soil.

As per IS 2720-part (16) Loading machines cylinder moulds $150 \mathrm{~mm}$ diameter and $175 \mathrm{~cm}$ height having a collar of $50 \mathrm{~cm}$ length and perforated base which is detachable, compaction rammer. IS sieves of $20 \mathrm{~mm}$, filter paper, balance. .By using $20 \mathrm{~mm}$ sieve sample is sieved. $5 \mathrm{~kg}$ of sample is taken. Then add water to the sample upto it reach optimum moisture content After adding the water mix the sample gently at the bottom of the mould spacer disc is placed and over the spacer filter paper is Placed The sample is divided into 5 parts. The mould is cleaned and oil is applied. fill the mould of one fifth with prepared sample of soil. .By giving 56 blows soil is compacted same process is repeated upto 3 layers collar is attached after $3^{\text {rd }}$ layer. Same process is repeated. A weight of $2.5 \mathrm{kgs}$ is placed on the soil surface top. on testing machine specimen is placed and plunger is brought near to soil sample a load of four $\mathrm{kgs}$ is applied. Dial reading is adjusted. penetration power rate $1.2 \mathrm{~mm}$ per min.. Table 6 showing the observation and calculations CBR test. And Fig 2 shows the graph of the CBR results.

Table 6. Observations and calculations

\begin{tabular}{|l|l|l|l|}
\hline Penetration & $\begin{array}{l}\text { Proving } \\
\text { Ring } \\
\text { Reading }\end{array}$ & $\begin{array}{l}\text { Load } \\
\text { Intensity } \\
\left(\mathrm{Kg} / \mathrm{cm}^{2}\right)\end{array}$ & $\begin{array}{l}\text { Standard } \\
\text { Load } \\
\left(\mathrm{Kg} / \mathrm{cm}^{2}\right)\end{array}$ \\
\hline 0.0 & 0 & 0 & \\
\hline 0.5 & 22 & 1.45 & \\
\hline 1.0 & 38 & 2.50 & \\
\hline 1.5 & 52 & 3.42 & 70 \\
\hline 2.0 & 75 & 4.93 & \\
\hline 2.5 & 93 & 6.11 & \\
\hline 3.0 & 110 & 7.23 & 7.76 \\
\hline 4.0 & 118 & 8.61 & \\
\hline 5.0 & 131 & 9.47 & \\
\hline 7.5 & 144 & 10.52 & \\
\hline 10.0 & 160 & 11.31 & \\
\hline 12.5 & 172 & & \\
\hline
\end{tabular}

\subsubsection{Calculations}

Load intensity = Proving ring reading*load factor/Area of plunger
Load factor $=1.29$

$$
=22 * 1.29 / \pi / 4 * \mathrm{~d}^{2}=22 * 1.29 / \pi / 4 * 5^{2}=
$$

$1.45 \mathrm{Kg} / \mathrm{cm}^{2}$

$\mathrm{CBR}$ at $2.5 \mathrm{~mm}$ penetration $=6.11 / 70 * 100=8.72 \%$

$\mathrm{CBR}$ at $5.0 \mathrm{~mm}$ penetration $=8.61 / 105 * 100=8.2 \%$

So Value of $\mathrm{CBR}=8.72 \%$

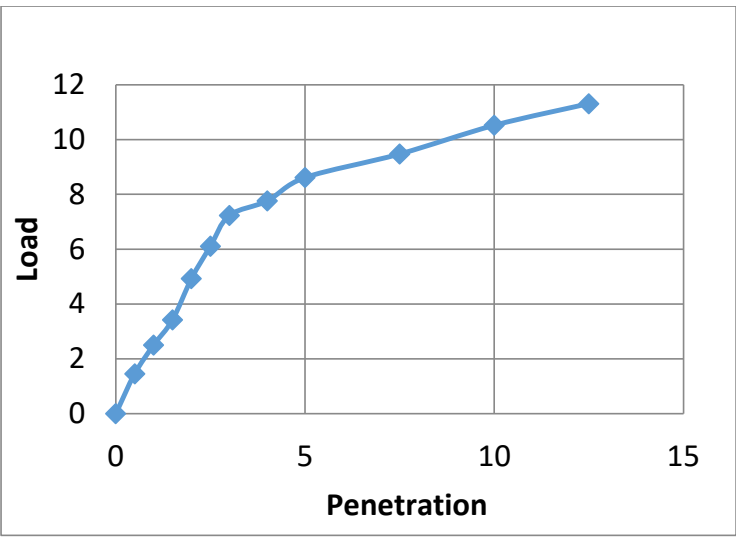

Fig. 2 Result of the CBR value (8.72\%).

\subsubsection{Penetration test}

To find the bituminous material consistency. Take A flat bottomed cylindrical metallic dish of $55 \mathrm{~mm}$ in diameter and $35 \mathrm{~mm}$ depth. Tray, water bath, needle, thermometer, penetration apparatus and timer. A Sample of bitumen is taken and poured into a container. The depth of bitumen in container should be $15 \mathrm{~mm}$. The container is placed in a water bath at $25^{0} \mathrm{C}$ temperatures for one hour. After one hour the sample is taken out from water bath. Then it is placed in penetration apparatus. The needle is brought in contact with the surface of bitumen sample. The dial reading is noted. The needle is released and it is allowed to penetrate for 5 seconds and dial reading is noted. At least 3 penetration readings should be taken on same sample. The mean value of three readings is taken. Table 6 Observation \& calculation Penetration Test.

Table 6 Observation \& calculation Penetration Test.

\begin{tabular}{|l|l|l|l|}
\hline $\begin{array}{l}\text { Penetration of dial } \\
\text { reading }\end{array}$ & $\begin{array}{l}\text { Trial } \\
1\end{array}$ & Trial 2 & Trail 3 \\
\hline Initial & 200 & 264 & 333 \\
\hline Final & 264 & 333 & 407 \\
\hline Penetration value & 64 & 69 & 74 \\
\hline
\end{tabular}

Mean Penetration value $=(64+69+74) / 3=69$

The penetration value is 69 . Based on this value we will find out the grade of bitumen.As per IS Code 73:2006

Table 7 Observation \& calculation 


\begin{tabular}{|l|l|}
\hline BITUMEN GRADE & PENETRATION VALUE \\
\hline S-35 & $30-40$ \\
\hline S-45 & $40-50$ \\
\hline S-55 & $50-60$ \\
\hline S-65 & $60-70$ \\
\hline S-90 & $80-100$ \\
\hline S-200 & $175-225$ \\
\hline
\end{tabular}

As the penetration value is 69 , So the grade of bitumen is S-65. Results of the Penetration value are 69. Grade of Bitumen is S-65.

\subsubsection{Bitumen extraction test}

To find the amount of bitumen present in bitumen concrete mixture. Bitumen extractor machine, filter paper, benzene petrol/diesel, aggregate-bitumen mixture, centrifuge, balance, beaker foe collecting extracted material. Required.Take some sample of bitumen and weigh the sample as $\mathrm{W}_{1}$. Then the sample is placed in the cup of centrifuge. Note down the weight of filter paper as $F_{1}$.Add benzene into the cup upto the sample top.The benzene and bitumen will drain out completely from beaker. Now again add more benzene and repeat the same process.Run the centrifuge again ang again until total bitumen is extracted.Weigh the extracted material as $\mathrm{W}_{2}$. Remove the filter paper and dry it in oven at $1050^{\circ}$ to $1100^{\circ}$ temperature and allow it to cool to the room temperature. Then again weigh the filter paper as $F_{2}$

\subsubsection{Calculations}

Weight of the sample $\mathrm{W}_{1}=1236$ gms.

Weight of the filter paper before test $F_{1}=2.5$

Weight of the filter paper after test $\mathrm{F}_{2}=3.1$

Weight of the aggregate after extraction

$W_{2}=1175$ gms. $W_{3}=F_{2}-F_{1} W_{3}=3.1-2.5 W_{3}=0.6$

Bitumen Percentage $=W_{1}-\left(W_{2}+W_{3}\right) / W_{1} * 100$

$=1236-(1175+0.6) / 1236 * 100=4.93 \%$

Results obtained that bitumen content is $4.93 \%$

\section{Road construction activities}

\subsection{Earth work excavation}

Excavation is necessary to cut down the trench of excessive masses of earth and to prepare a strong base for the pavement layers. Required excavations will be carried out accordane to the directions laid down as in a manner approved by the engineers. Excavation of the site shall mostly be made with the help of the excavators like Ex-200, Ex-100 or other suitable plants which depends upon the stretches and quantum of the work.Excavation shall be done up to a depth of $1 \mathrm{~m}$ below the ground level directed by the engineer.

\subsection{Embankment Construction}

The materials which are excavated will be dumped in the site at required location. The materials has to be spread in layers of uniform thickness not excluding $200 \mathrm{~mm}$ compacted thickness over the entire width of the embankment and shall be graded with motor grades to the required camber. Water content of the material must be checked. Then the material has to be compacted with the help of vibratory roller or 8 to 10 ton of static weight. Each layer is compacted thoroughly to the specified specifications until the layers becomes strong enough.

\subsection{Sub Grade Construction}

The material used for the subgrade shall be usually soil, morrum, gravel, a mixture of these or any other approval material. Material using for the subgrade should have a sufficient quality which in term indicates the property of the material. It should be free of logs, roots, stumps, rubbish for any ingredients like deteriorate or affect the stability of the subgrade. The CBR value of this particular soil is mentioned in the technical specifications of the test results. The material shall be dumped in the site at respective location in particular layers. Loose voids shall be and replaced with the required material.This subgrade layer is filled with gravel, soil, morrum or a mixture of these or any other approved materials up to a depth of $0.5 \mathrm{~m}$ from the bottom of the trench.

\subsection{Granular Sub-Base Course}

GSB is a naturally obtained construction material, which is used for the construction of road as a subbase layer.Granular Sub-Base layer is laid just above the compacted sub-grade layer in the road foundation.GSB consists of natural sand, crushed gravel, crushed stone and it acts as a filter media for road or highway.Maximum particle size in GSB is $75 \mathrm{~mm}, 53 \mathrm{~mm}, 26.5 \mathrm{~mm}$. The standard grades are reffered from table 400-2 specifications. This GSB acts as a sub-base course which provides structural support to the base course and surface course. It mainly prevents and resists the sub grade soil to enter into the above pavement layer.Mostly the size of the aggregates used in GSB will be $10 \mathrm{~mm}, 8 \mathrm{~mm}, 6 \mathrm{~mm}$, and $\mathrm{M}$ sand.

\subsection{Wet mix macadam}

Wet mix macadam (WMM) is a layer laid above the GSB. This WMM is a laying method contains of spreading and compacting of clean, crushed, well graded granular materials on GSB layer. It is a nonbituminous base course which consists of aggregates as $70 \%$ and $\mathrm{M}$ sand of $30 \%$. Aggregate sizes used in 
WMM are $40 \mathrm{~mm}, 20 \mathrm{~mm}, 12 \mathrm{~mm}, 10 \mathrm{~mm}$ including $\mathrm{M}$ sand.The amount of water absorption for aggregates used in WMM should be less than $2 \%$ This material in WMM course should be mixed up with water upto a desired water content. Approximately the water content may be 6 percent. This layer act as a binder material. Compaction of the aggregate should be done thoroughly by sprinkling the required amount of water percent.The material shall be uniform and have to be free of pockets of fine material

\subsection{Application of Prime Coat}

Prime coat is an application of a low viscosity bitumen to the granular base from the preparation of initial layer (surface course) of bitumen. The prime coat is sprayed over the wet mixed macadam layer by using sprayer. This coat will bond the loose material particles together and harden the base surface which in terms provide a work platform for the construction equipment. Materials used in prime coat back bitumen or emulsified bitumen (diluted)

\subsubsection{Dense Bituminous Macadam Construction}

Dense Bituminous Macadam (DBM) is a binder course which helps the road pavement to withstand the maximum load of more number of commercial vehicles. Mix proportion is of DBM mix will consists of coarse aggregate, fine aggregate and filler in required proportions. Proper blending of the aggregations must be made so that final graduation will reach the satisfactory limits.

\subsubsection{Coarse aggregate}

The DBM mix should contain coarse aggregate material which retains on $2.36 \mathrm{~mm}$ sieve. It should be preferably hydrophobic and must have low porosity. In some situations where it founds to have more porous aggregates, then it must be provided with extra bitumen for absorption by aggregates, then it must be provided with extra bitumen for absorption by aggregates to satisfy the design criteria.

\subsubsection{Fine aggregate}

The DBM mix will consists of fine aggregate material which tends to pass through $2.36 \mathrm{~mm}$ sieve and retained on 75 microns sieve. This material consists of natural sand, crushed screenings or combination of both. It should be clean, durable, hard, dry and free from any organic matter.

\subsubsection{Filler}

DBM mix also consists of filler material which acts as binders. The material should pass from 75 micron sieve. Generally, filler material includes cement, hydrated lime, stone dust, fly ash or any other nonplastic mineral matter. Usually, requirement of filler is reached out by the material passing through 75 microns sieve in fine aggregate, if FA is not sufficient then extra filler is to be added. Extra filler shown in the table

Table 7 sieve and $\%$ of passing

\begin{tabular}{|l|l|}
\hline Sieve (microns) & $\%$ passing \\
\hline 600 & 100 \\
\hline 150 & At least 90 \\
\hline 75 & $>70$ \\
\hline
\end{tabular}

\section{Preparation of mix and construction}

Preparation of mix according to the specified proportions is carried out in near by hot mix plant of adequate capacity. The mix is them transported by tipper truck to the site and then it is laid by using mechanical power. A layer of $75 \mathrm{~mm}$ and DBM mix is laid over the road by providing a camber of $5 \mathrm{~mm}$ on either sides of divides. Then it is compacted to $60 \mathrm{~mm}$ thickness binder course is uniformly laid.

\subsection{Application of Tack coat}

The layer between dense bituminous concrete $(\mathrm{BC})$ is called Tack coat. The main purpose of the tack coat is to make bond between DBM course and BC course. If tack coat is absent, bituminous concrete will tends to cause slip under the traffic load and failure of pavement will occur due to spalling of bituminous concrete. If $\mathrm{BC}$ is directly laid over $\mathrm{DBM}$, the bitumen is $\mathrm{BC}$ will not be enough to form a long lasting effective bond between those two layers.

\subsection{Bituminous concrete (BC) Construction}

Bituminous concrete is a construction material which is mainly used for the paving of roads. It is obtained from blending of stones and other forms of aggregate materials mixed together by a binding agent. This binding agent is known as "bitumen" and it is a byproduct of refining of petroleum or crude oil. This bitumen is easy to produce, reusable, non-toxic and it is a strong binder. For required bituminous concrete material, at least one single sample for every 100 tonnes of the mix is to be needed for testing. Test on bitumen is carried out in hot mix plant. The tested sample is conveyed to the site and laid over the DBM layer. This BC course will be laid with a thickness of $45 \mathrm{~mm}$ and it reaches to $30 \mathrm{~mm}$ after compaction. Routine checks on the thickness of BC course should be carried out at site by using gauge. The surface should be then compacted by rollers without any undulations and the surface must be smooth enough for the free moment of traffic. 


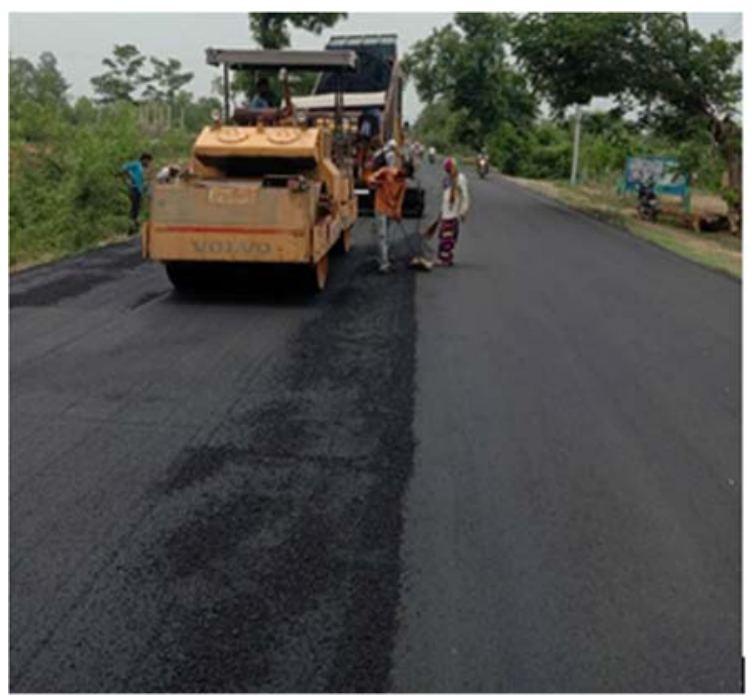

\subsection{Application of seal coat}

Seal coat is also termed as pavement sealing. It is process of applying a coat to protect bituminous concrete based pavements. It gives protection to the $\mathrm{BC}$ course which in terms protects from the elements like water, oils and U V damage. Mixing for seal coat before laying should be done thoroughly until the sealer reaches uniform consistency. Seal coat application is also laid by sprayers.

\subsection{Divider construction}

Divider is a concrete structure which acts as median to the carriageway on either sides. Technically divider is termed as "Median". They are mainly meant for the following purposes To avoid the accidents., To install and regulate the traffic signs and traffic signals, To provide lighting systems for the road, In some cases of rural area, vehicles can be park on the median under any emergency, For the project considerations, the design for KKY road has been specified the divider dimension as $1.5 \mathrm{~m}$ width. Here the divider is constructed for a height of $1 \mathrm{~m}$ on the pavement surface. It is designed in such a manner where planting of trees can be made in between the median.

\subsection{Shoulder construction}

An adequate shoulder is essential part for all the highways. It provides the lateral stability for the pavement and acts as the lane in emergency conditions. It also protects the edges of the road. They often helps in draining out the rainwater flow through it. Hence, good graded materials are to be used for the shoulder construction.

\section{Quality management in construction}

Quality management system is a formalized system they are Customer Requirements. Various parameters related to quality are Quality planning, Quality assurance, Qualitycontrol, Quality improvement, Customersatisfaction The main principle of quality management is to improvement to work of customer's and focus on leadership. To increasing the productivity rate, etc .Quality assurance and quality control are two aspects of quality management

\subsection{Quality_Assurance}

Quality Assurance is defined as IS0 9000 defines a part of quality management focused on providing confidence that quality requirement will be fulfilled. Quality Assurance is mainly focused on defect prevention. Improving of quality of process and products . The work is done by process oriented.

The product development checking by quality assurance. .there shouldn't be any defects Quality assurance is done before the quality control.

\subsection{The Activities of quality assurance}

Planning,Data collection, Quality control , documentation, Evaluation, Reporting Activities.

\subsection{Quality control}

Quality control defines as quality standards and the quality control testing requirements. The Approval of the work done before the starting of the particular works. It generally focused on the identification of works. Quality control is mainly to correcting the defects .Improving the developments of product.Zero defects After completion of project there shouldn't be any defects.

\section{Equipments used in the construction Excavators}

Excavators are heavy equipment consisting of boom, stick, bucket and cab on a rotating platform house. Three types of excavators are used. Excavator100. Excavator 200, Excavator 300, 100, 200, 300 represent size of bucket.

\subsection{Dumpers}

Dumpers are used for transportation of bulk materials such as sand, gravel and dirt. A dump truck consists of hydraulically operated open-box bed hinged at the rear, the front of which can be lifted to allow the contents to be deposited on the ground behind the truck at the site of delivery.

\subsection{Road Roller}

Road Roller is used for compaction of soil, gravel, concrete in the construction of roads. The rollers are used to thoroughly compact the materials and they do 
not come too loose. Rollers have diesel engine, and a canop y to protect the driver, and a drum, the drum may be vibratory smooth or static smooth drum, to measure the level of compaction and water a compaction meter is provided.

\subsection{Mechanical Paver}

Mechanical paver is used to laying the bitumen on the roads. The bitumen mix is loaded into the mechanical paver through tipper Then it spreads on other side and lays The bitumen. This machine also helps in fixing the gradient of road on either side. Laying of bitumen through paver should ensure that no small lumps of aggregate or stone to be left over the surface. The standard width of paving is $8-12 \mathrm{ft}$ (2.4-3.7). Mechanical paver also helps in partial compaction of bitumen on the surface of road.

\subsection{Sprayer}

Sprayer is usually known as bitumen distributor. A bitumen sprayer works as a controlling agent of the flow of bitumen and to spray the bitumen evenly on the road surface. This is mainly used for laying of prime coat, tack coat and seal coat. Spraying is generally made before the laying of hot mix bitumen on the road surface. The most basic quality of this sprayer is to store the bitumen in a tank, heat when requires and spray on the road easily.

\section{Conclusions}

Construction of flexible pavement for KKY road is followed the specified design data.CBR value for soil sub grade used for the road construction is under allowable limit i.e., 7.32\%.Tests required for the materials used in the construction are tested in treatment plant and adequate results have been obtained. Traffic survey for KKY road is made through manual counting and allotted a design period of 20 years for the pavement. According to design of pavement, the each layers has: following thickens are SUB GRADE , GSB , WMM , DBM, BC 500mm, $250 \mathrm{~mm}, 250 \mathrm{~mm}, \quad: 75 \mathrm{~mm}, 45 \mathrm{~mm}$. For the above design, the meterial and aggregate tests conducted according to IS code and they are within design limits. Finally, a complete general report for Flexible Pavement Design of KKY road with a reach of $97 / 4$ to $99 / 4[2 \mathrm{~km}]$ is written considering all the steps involved in construction. Acknowledgement :Thank to the contractors who is executed the work and supported .

\section{REFERENCES}

1. A. ASHTO guidelines for design of pavements structures. American association of state highways and transportation officials. (1993)
2. K. Abdesh Sinha, Satish Chandra and Praveen kumar. Finite element analysis of flexible pavement with different subbase materials. Indian highways, new delhi. (2014)

3. M.Amarantha Reddy, Sudhakar Reddy k, and pandey , B.B, Design of CBR of subgrade of flexible pavements. (2001)

4. IRC: 37-2001. Guidelines for the design of flexible pavements. IRC, New Delhi.

5. K. Kranthi Kumar, R. Rajashekar, M. Amarnantha Reddy and B.B pandey, reclaimed asphalt pavements in bituminous mixes. Indian Highways 12-18. (2014)

6. M.T Rahman, Mahumud K and Ahsan. S Stress. Strain characteristics of flexible pavements using finite element analysis. (2011)

7. M.S Ranadive, tapase, AB Investigation of behavioral aspects of flexible pavements under various conditions by finite element method. (2013)

8. J.M Sadeghi and Fathali, M. Deteriotation analysis of flexible pavements under overweight vehicles. (2007)

9. E C G.Zuo, Drumn, and Meier, R.W Environmental effects on the predicted service life of flexible pavements. (2007)

10. Design of manual for low volume sealed Roads Malawi, Ministry of transport and public works (2013)

11. SI .(Standard specifications) for roads and bridges work, department of roads July 2001.

12. .S.K Singh., Dixit, A., Kumar, D.R. Technology, Optimization of the design parameters of modified die in hydro-mechanical deep drawing usingLS-DYNA, International Journal of Advanced Manufacturing, 38 (1-2), pp. 32-37 (2008)

13. S.Patel, , Rana, R.S., Singh, S.K. Study on mechanical properties of environment friendly Aluminium E-waste Composite with Fly ash and E-glass fiber Materials Today: Proceedings, 4 (2), pp. 3441-3450. (2017)

14. .K.S Prasad, Gupta, A.K., Singh, Y., Singh, S.K. A Modified Mechanical Threshold Stresss Constitutive Model for Austenitic Stainless Steels Journal of Materials Engineering and Performance, 25 (12), pp. 5411-5423, (2016).

15. U. Pandey, U., Purohit, R., Agarwal, P, Kumar Singh, S.Study of Fabrication, esting and Characterization of $\mathrm{Al} / \mathrm{TiC}$ Metal Matrix Composites through different Processing Techniques, Materials Today: Proceedings, 5 (2), pP 4106-4117., (2018) 